\title{
Labyrinthe
}

18 | 2004 (2)

La Recherche dans tous ses éclats

\section{Les écritures pour marionnettes entre 1890 et 1935}

En France, en Espagne et en Belgique

\section{Hélène Beauchamp}

\section{CpenEdition}

Journals

Édition électronique

URL : http://journals.openedition.org/labyrinthe/202

DOI : $10.4000 /$ labyrinthe.202

ISSN : 1950-6031

Éditeur

Hermann

Édition imprimée

Date de publication : 15 juillet 2004

Pagination : 17-20

\section{Référence électronique}

Hélène Beauchamp, «Les écritures pour marionnettes entre 1890 et 1935 », Labyrinthe [En ligne],

18 | 2004 (2), mis en ligne le 20 juin 2008, consulté le 20 avril 2019. URL : http://

journals.openedition.org/labyrinthe/202 ; DOI : 10.4000/labyrinthe.202 


\section{LES ÉCRITURES \\ POUR MARIONNETTES \\ ENTRE 1890 ET 1935 \\ En France, en Espagne et en Belgique}

Hélène BEAUCHAMP

helenebeauchamp@hotmail.com

Ce titre de travail, peut-être provisoire, permet pour le moment d'expliciter les ambitions de cette thèse. Cette recherche a commencé par la prise en compte d'un fait: le foisonnement d'initiatives théâtrales autour du théâtre de marionnettes en Europe au tournant du XIX ${ }^{e}$ et du $\mathrm{XX}^{\mathrm{e}}$ siècle, période traditionnellement décrite comme celle de la «crise du théâtre», du passage chaotique à la modernité. Cet engouement pour le théâtre de marionnettes, appelé à «régénérer» la scène par nombre de dramaturges et hommes de théâtre, commence dans les années 1890 avec le symbolisme en France et le modernismo en Espagne, et se poursuit, sous des formes différentes, jusque dans les années 1930. Il s'agissait alors de comprendre les raisons de la forte présence des marionnettes dans la réflexion et les créations de cette époque.

Les écritures pour marionnettes se sont développées dans un mouvement d'expérimentation théâtrale. Quelle que soit leur orientation esthétique, les différentes pièces du corpus sont réunies par une volonté commune de révolutionner l'écriture dramatique et la mise en scène de leur temps. Cette radicalité se révèle surtout au niveau esthétique : il s'agit de rompre avec le réalisme de la seconde moitié du XIX ${ }^{\mathrm{e}}$ siècle, notamment pour les auteurs du début de notre période, qui ont évolué dans la mouvance du symbolisme et du modernismo. D'autres textes, souvent plus tardifs, outre cet héritage esthétique du symbolisme, se chargent d'une dimension politique et sociale, où la révolution esthétique se double d'un contenu idéologique mis en valeur par le recours à la puissance grotesque et satirique de la marionnette. Malgré l'aspect expérimental et la diversité de ces recherches autour 
de la marionnette, l'ensemble du mouvement a, semble-t-il, véritablement contribué à engager l'art théâtral vers une autre vision du théâtre qui place la distanciation au cœur de la dramaturgie.

Sur le plan esthétique, le théâtre de marionnettes apparaît comme un concept englobant, symbole d'un théâtre total, d'un art de démiurge qui fait appel à la peinture, à la musique (plusieurs «opéras pour marionnettes » ont été écrits pendant cette période), à la danse (avec par exemple la marionnettisation des danseurs des Ballets russes). Dans ce contexte, il fallait envisager la notion «d'écritures pour marionnettes » dans un sens assez large. Les textes de notre corpus présentent indifféremment de vraies marionnettes, des effigies diverses, des acteurs marionnettisés ou même des êtres dont la nature est imprécise.

Des auteurs aujourd'hui consacrés par l'histoire littéraire se sont inspirés fortement de ce modèle esthétique. Pour certains d'entre eux, cet aspect de leur réflexion et de leur création théâtrale a été peu mis en valeur, souvent considéré comme mineur. Pourtant, pour des auteurs comme Alfred Jarry ou Federico García Lorca, la référence au théâtre de marionnettes frappe par sa permanence. Notre corpus comprend, outre les pièces «pour marionnettes» de ces deux auteurs, des œuvres de Pierre Albert-Birot, Paul Claudel, Maurice Maeterlinck, Michel de Ghelderode, Ramón del Valle-Inclán, Jacinto Grau, Rafael Alberti. Autour de ces œuvres se développe tout un corpus secondaire, d'auteurs moins importants ou ayant écrit occasionnellement pour les marionnettes (Maurice Bouchor, Edmond Rostand, Émile Malespine, Manuel de Falla, Santiago Rusiñol...), mais qui tous témoignent d'un mouvement qui s'est étendu à toute l'Europe.

Le modèle esthétique de la marionnette, largement inspiré par le théâtre de marionnettes populaire, est invoqué pour révolutionner la mise en scène, la théorie du théâtre, mais aussi l'écriture dramatique, dans une réaction généralisée contre le réalisme au théâtre. Ce travail repose donc à la fois sur des textes théoriques, des textes dramatiques et des études de mise en scène. On oppose alors la marionnette impersonnelle à l'acteur trop humain, une dramaturgie critique, méta-théâtrale et distanciée au théâtre de la fin du XIX ${ }^{e}$ siècle. La seconde moitié du XIX ${ }^{e}$ siècle est en effet caractérisée par le développement d'un théâtre bourgeois à vocation réaliste, bientôt battu en brèche par le naturalisme et les expériences d'André Antoine au Théâtre-Libre. Ce théâtre bourgeois, dont les représentants en France sont Émile Augier, 
Alexandre Dumas fils ou Victorien Sardou, malgré ses prétentions au réalisme, reste très moralisateur, peu inventif, soumis aux exigences du bon goût, et se développe sur une scène aux conventions désuètes, où la toile peinte illusionniste règne en maître. Plusieurs réactions naissent contre cette conception du théâtre dans toute l'Europe à partir des années 1890, visant à rétablir la place de l'imagination et de la fantaisie dans l'art théâtral. Parmi les solutions proposées, le théâtre de marionnettes occupe une place de choix, et se charge d'une dimension polémique.

Cet esprit de rénovation esthétique se combine à une charge politique et sociale qui apparaît le plus souvent dans les textes d'aprèsguerre de Valle-Inclán, Lorca, Rafael Alberti ou Michel de Ghelderode. Il s'agit, à travers le prisme de la marionnette, de présenter une vision parodique d'un monde sans conscience et sans morale, où l'armée, la religion, les idéologies du temps sont la cible de ces textes à vocation subversive.

On pourrait penser qu'il y a un grand écart esthétique entre les textes du corpus, mais la marionnette les réunit. En effet, la plupart d'entre eux, avec, d'un côté, les pièces tragiques de Maeterlinck et, de l'autre, les pièces politiques de Rafael Alberti, proposent un mélange d'influences assez inédit à l'époque, une fusion du métaphysique et du grotesque dans une esthétique tragi-comique. Cette tension générique est pour nous constitutive de la spécificité de ce corpus, et semble liée fondamentalement à la tradition du théâtre de marionnettes populaire, qui pouvait à la fois explorer les terrains spirituels et religieux et le comique de la farce.

Après avoir pris en compte la destination déstabilisatrice de ces écritures «pour marionnettes », il fallait voir dans quelle mesure elles proposaient une esthétique digne d'intérêt et éventuellement fondatrice de conventions ou de principes appelés à un avenir. Malgré leur caractère parfois expérimental, des traits forts, que l'on retrouvera ensuite tout au long du XX⿳亠丷厂 siècle, se dégagent de ces écritures. À travers elles s'engage une transition vers un théâtre synthétique et stylisé, à la fois savant et populaire, qui s'offre une liberté générique totale. Sur le plan dramaturgique, l'usage ou la référence à la marionnette met en place tout un système parodique et tragi-comique qui conduit le théâtre vers une des directions les plus marquantes du $\mathrm{XX}^{\mathrm{e}}$ siècle: une esthétique de la distanciation. 
Ce domaine a été peu exploré par la recherche comparatiste depuis le travail fondateur de Didier Plassard dans L'Acteur en effigie ${ }^{1}$. Les marionnettes et les effigies sur la scène ayant été amplement étudiées par ce dernier, nous avons décidé de centrer notre regard sur la dramaturgie, même si l'étude scénique, indispensable en matière de marionnettes, reste pour nous un souci constant. Passer par l'Espagne et la Belgique était donc aussi une façon de poursuivre la recherche commencée par Didier Plassard sur ce mouvement européen.

Ces écritures pour marionnettes constituent un «laboratoire», dans leur caractère de «théâtre de recherche » et de «transition». Elles ont aussi l'ambition d'engager une «révolution théâtrale », terme qui reflète une articulation entre un aspect radical et destructeur très présent dans ces textes et l'établissement de nouvelles conventions, d'un «nouvel ordre dramaturgique» fondé principalement sur un jeu de distanciation théâtrale.

1. L'Acteur en effigie: figures de l'homme artificiel dans le théâtre des avant-gardes historiques (Allemagne, France, Italie), Lausanne, L'Âge d'Homme, Charleville Mézières, Institut international de la marionnette, collection «Théâtre années vingt», 1992. 